\title{
Influence Mechanism of Grouting on Mechanical Characteristics of Rock Mass
}

\author{
Zhang Jixun, ${ }^{1,2}$ Shu Jiaqing, ${ }^{3}$ Ren Xuhua, ${ }^{1}$ and Ren Hongyun ${ }^{1}$ \\ ${ }^{1}$ College of Water Conservancy and Hydropower, Hohai University, P.O. Box 210098, Nanjing, China \\ ${ }^{2}$ State Key Laboratory of Hydrology-Water Resources and Hydraulic Engineering, Hohai University, P.O. Box 210098, Nanjing, China \\ ${ }^{3}$ Jiangsu Electric Power Design Institute, P.O. Box 210098, Nanjing, China
}

Correspondence should be addressed to Zhang Jixun; hhu_zhangjx@163.com

Received 7 July 2013; Accepted 12 August 2013

Academic Editor: Song Cen

Copyright (C) 2013 Zhang Jixun et al. This is an open access article distributed under the Creative Commons Attribution License, which permits unrestricted use, distribution, and reproduction in any medium, provided the original work is properly cited.

Grouting technology has been widely used in all fields of geotechnical and civil engineering. Prospective engineering objectives including reinforcement of rock mass and groundwater leakage treatment can be achieved by grouting which will change the mechanical parameters of rock mass such as strength, elastic modulus, and coefficient of permeability. In this paper, rock mass is assumed as a composite material consisting of rock particles and random microcracks initially. Since part or all of the cracks will be filled with cement slurry after grouting, rock mass consists of rock particles, grout condensate, and some or no random microcracks after grouting. The damage constitutional law of the mesoscopic element is established based on the theory of mesoscopic damage mechanics. With the heterogeneity of the components of rock mass considered, the variation of mechanical characteristics of rock mass is studied before and after grouting. And the influence mechanism of grouting on rock mass is investigated at mesoscale level.

\section{Introduction}

Grouting is a technique that makes use of pressure to inject slurry into the rock cracks or cracks in buildings, in order to improve the physical mechanical characteristics. It has been applied in almost all the domain of rock and civil engineering and its functions are enhanced gradually with the growing grouting technique. Grouting can obtain the objectives of reinforcement of rock mass and groundwater leakage treatment by filling, pressing, conglutinating, and solidifying.

Since 1802, when grouting technique was used for the first time to restore the gravelly soil foundation of a tide gate, which is eroded by water stream, by the French civil engineer Charles Berigny, the technique has been developed for more than 200 years and great progress has been made.

Yin and Wen [1] studied the properties and reaction mechanism of dolomite limestone-water glass grout; Ge [2] studied the development and prospect of chemical grouting techniques; Tang [3] introduced the application of grouting technique to treatment of limestone cave surge; Hao [4] has expounded high pressure grouting technique for fault stabilization treatment at karstic ground and analyzed action mechanism of high pressure grouting and means of grouting pressure control; Hao et al. [5], Yang et al. [6], and Luo et al. $[7,8]$ studied crack grouting in rock mass and have developed the corresponding computer simulation procedure, respectively; Li et al. [9] proposed the overall evaluations of crack grouting effect in concrete dam; Li et al. [10] have discussed numerical modeling of grouting in geoengineering. Present theory and practice research mainly concentrate on the grouting material, craft, technology, grouting and its influence, and flow quality of cement slurry in rock mass cranny, but it is seldom to see the research about how grouting improves the mechanical characteristics of rock mass. This paper attempts in this aspect to make the preliminary study.

The current research of material characteristics is mainly focused on three scales which are micro, meso- and macroscales. It is generally considered that the mechanical characteristics of materials in a scale can be analyzed and explained in a lower scale (Zhu et al. [11]). For the research of how grouting improves the macromechanical characteristics, 
the rock material is thought to be made up of rock particles and random cracks in a mesoscale and their properties are thought to be heterogeneous as well. After grouting part or all of the original cracks are filled with cement slurry and meanwhile it can be regarded that the rock is made up of rock particles, grout condensate, and some or no cracks. Furthermore, the damages constitutive model can be built and numerical experiments can be developed for analyses of the change of mechanical characteristic during the grouting.

\section{Simulation of Fractured Rock Mass}

There are many cracks in the natural rock mass, and rock mass is a complicated geologic body composed of rock block and random cracks. The natural or artificial cracks have significant influence on the macromechanical characteristics of rock mass. Grouting makes use of the cracks in the rock mass and injects the slurry into the rock mass in order to increase the strength and prove the leakage.

Zhu et al. [11] proposed a method to simulate the joint network. (1) Use parallel-line method, statistical window method, or digital holography method to measure the geometrical characteristics of cracks; parameters that need to be measured include the angle of strike, the dip angle, the fracture interval, and the fracture aperture. Then establish a suitable statistic model. (2) According to the principle of geostatistics and Monte Carlo method, the joint network of the rock mass can be drawn. Chen [12] developed 3D network numerical modeling technique for random discontinuities of rock mass. Based on statistical window method, geological sketch, and digital videography, $\mathrm{Hu}$ et al. [13] developed a new method for rock mass fine structure in situ mapping. From the method rock mass structure model can be established through the in situ mapping after obtaining the basic geological information. Detailed geological investigation is the soul of the fine structure description.

\section{Heterogeneity of Materials}

Strictly speaking, all materials in nature are more or less heterogeneous; the difference is the degree of heterogeneity. Scholars at home and abroad in academe have done long exploration on heterogeneous materials and achieved great progress in recent 20 years. Heterogeneous materials has been a new discipline branch. Schlangen and Mier [14] simulated the typical failure mechanism of brittle concrete materials and structures using a simple lattice model; Blair and Cook [15] studied the nonlinear behavior and microheterogeneities in stress fields caused by variations of grain shapes and sizes; Tang and Kaiser [16] simulated unstable rock fracture using the finite element method (FEM) combined with models describing the material heterogeneities. Chen et al. [17] simulated the failure processes in 3D heterogeneous brittle materials. Professor $\mathrm{Xu}$ and his colleagues [18] did further researches for the past few years.

Rock mass is a typical heterogeneous material with cracks, bubbles formed during the diagenesis, and so on.

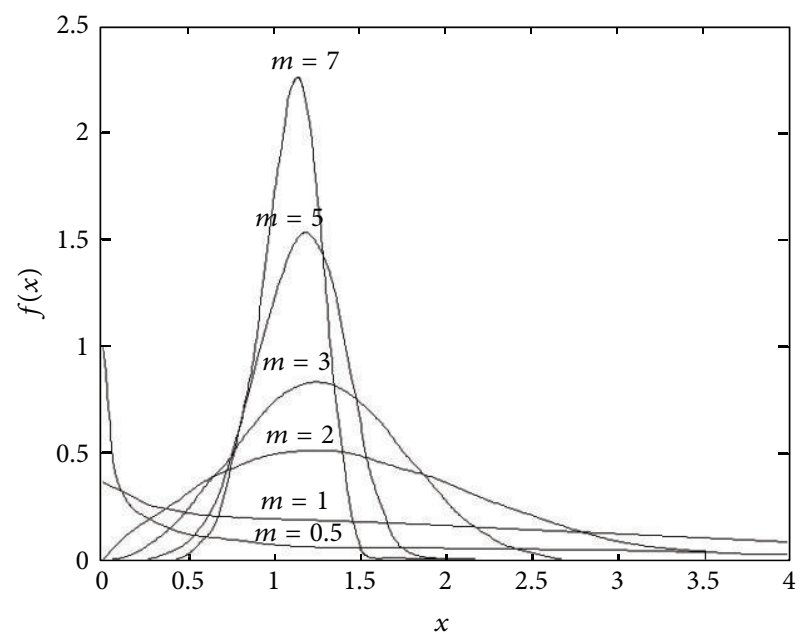

FIGURE 1: Weibull probability density function with different $m$.

Rock particles are also theoretically of heterogeneity, which can be described by the distribution of the mechanical parameters. Suppose that the mechanical parameter of mesoscopic elements obeys the Weibull distribution. Weibull distribution may have from one parameter to three parameters, among which Weibull distribution with two parameters is widely used. The two parameters are shape parameter and scale parameter separately.

Generally, we can use $W\left(\mu_{0}, m\right)$ to indicate two-parameter Weibull distribution; the function can be defined as follows:

$$
F(u)= \begin{cases}0, & u \leq 0 \\ 1-\exp \left(\frac{u}{u_{0}}\right)^{m}, & u>0\end{cases}
$$

The probability density function is

$$
f\left(u_{i}\right)=\frac{m}{u_{0}}\left(\frac{u_{i}}{u_{0}}\right)^{m-1} \exp \left(-\left(\frac{u_{i}}{u_{0}}\right)^{m}\right),
$$

where $u$ is the value of material parameter, the parameter $m$ defines the shape of the distribution function, and $u_{0}$ is the scale parameter, which is related to the mean value of all mesoscopic elements but is not the mean value. For the sake of convenience, $u_{0}$ is called typical value in this paper.

Parameter $m$ and parameter $u_{0}$ should be determined first when simulating heterogeneous materials. Figure 1 shows the Weibull distribution with different $m$.

From Figure 1, we learn that parameter $m$ reflects the dispersion degree of material parameter and can be called homogeneity index. When $m$ changes from small to large, the distribution function becomes longer and narrower; the material parameters of mesoscopic elements are almost the same and close to $u_{0}$. A larger $m$ implies a more heterogeneous material and vice versa. According to the known parameter $m$ and parameter $u_{0}$, we can generate $N$ random numbers which obey Weibull distribution, where $N$ is the number of mesoscopic elements. Then we can assign 
the random number to each element. Because the numbers are random and obey the statistic distribution, this method can simulate the heterogeneous materials perfectly, such as rock and concrete.

\section{Elastic Damage Constitutive Law of Mesoscopic Elements}

Elastic damage constitutive law is chosen to reflect the stressstrain relationship of mesoscopic elements Mohr-Coulomb criterion with a tension-off criterion is adopted to determine whether the element is fractured. Tension-off is prior to Mohr-Coulomb criterion; when an element meets tensionoff criterion, there is no need to check whether it meets Mohr-Coulomb criterion and the element is fractured. If an element does not meet the tension-off criterion, then we check whether it meets Mohr-Coulomb criterion.

When the applied load is small, the element is in elastic state; the stress-strain relationship can be expressed by Young's modulus and Poisson's ratio entirely. When the load increases, if the maximum tension stress of an element meets the threshold value, tension failure occurs, and if there is no tension fracture, check whether the stress condition meets Mohr-Coulomb criterion; if so, shear failure occurs.

The constitutive law of mesoscopic element under uniaxial load can be expressed in Figure 2.

Thus, in uniaxial tension stress condition, the damage variable is defined as follows:

$$
D= \begin{cases}0, & \varepsilon<\varepsilon_{t 0}, \\ 1-\frac{f_{t r}}{E_{0} \varepsilon}, & \varepsilon_{t 0} \leq \varepsilon<\varepsilon_{t u} \\ 1, & \varepsilon \geq \varepsilon_{t u} .\end{cases}
$$

And in uniaxial compress stress condition, the damage variable is defined as follows:

$$
D= \begin{cases}0, & \varepsilon>\varepsilon_{c 0}, \\ 1-\frac{\lambda \varepsilon_{c 0}}{\varepsilon}, & \varepsilon \leq \varepsilon_{c 0},\end{cases}
$$

where $E_{0}$ is initial Young's modulus; $f_{c 0}$ is the uniaxial compressive strength of mesoscopic element; $\varepsilon_{c 0}$ is the maximum compressive strain corresponding to $f_{c 0} ; f_{c r}$ is the residual strength of mesoscopic element under compress stress; $\lambda$ is defined as residual strength index; thus $f_{c r}=\lambda f_{c 0}$ and we assume that $f_{t r}=\lambda f_{t 0}$, where $f_{t 0}$ is uniaxial tension strength and $f_{t r}$ is the residual strength of mesoscopic element under tension stress. $\varepsilon_{t 0}$ is the maximum tension strain corresponding to $f_{t r}$ and can be called threshold tension strain and $\varepsilon_{t u}$ is ultimate tension strain, $\eta$ is defined as ultimate strain index; thus $\varepsilon_{t 0}=\eta \varepsilon_{t u}$. When $\lambda$ is large, the constitutive law showed in Figure 2 becomes elasto-brittle-plastic law.

\section{Numerical Simulations}

The geometrical model of the fractured rock in a plot window is established based on fine structure description method which was introduced in $\mathrm{Hu}$ et al. [13] research paper,

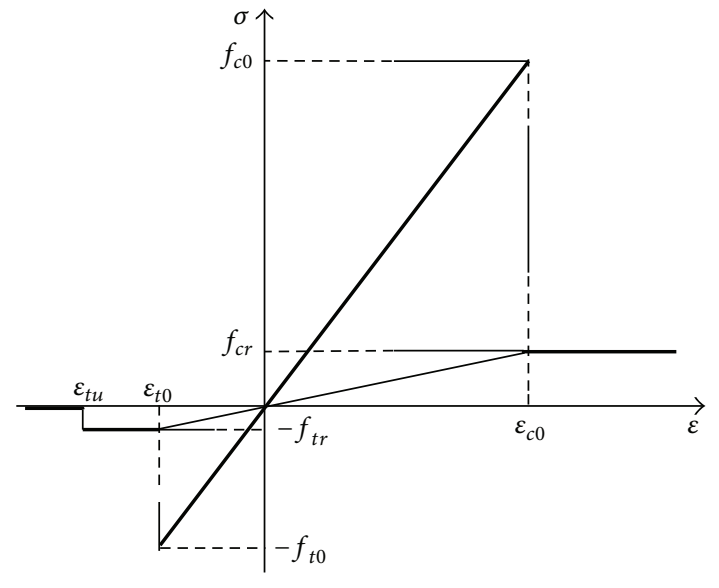

FIGURE 2: Elastic damage constitutive law of element subjected to uniaxial stress.

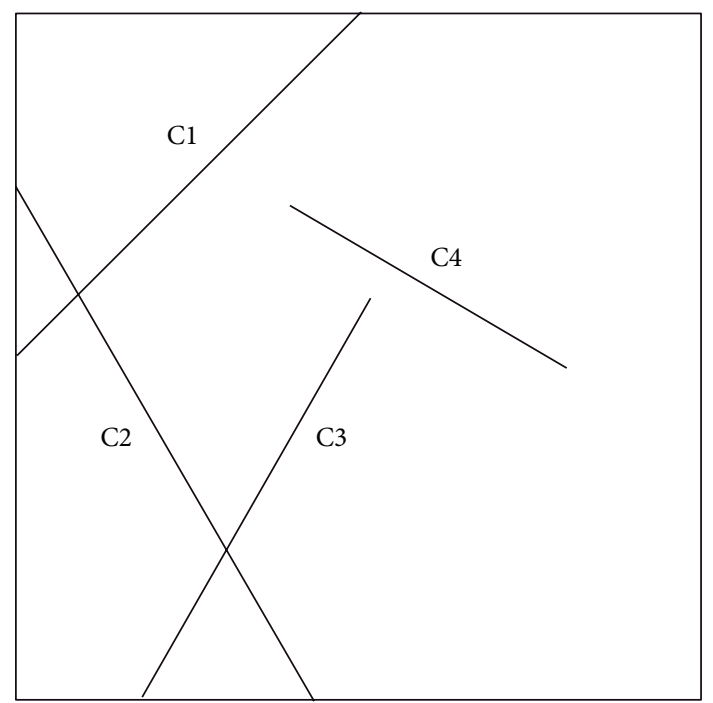

FIGURE 3: Geometry model of the fractured rock.

considering that the fractured rock mass is made up of two parts which are rock block and microcracks. The model with the size of $1.0 \mathrm{~m} \times 1.0 \mathrm{~m}$, as shown in Figure 3, contains four random cracks.

The model is meshed into $500 \times 500$ square elements with the same size. For the mesoscopic elements that are cut by cracks, the rock particle elements change into crack elements by modifying the mechanical characteristics, and crack elements change into cement slurry elements after grouting. The heterogeneity of strength and elastic modulus is taken into account and there is no dependence upon each other. The material properties are listed in Table 1.

The bottom of the specimen is constrained, and the lateral sides are free. The specimen is compressed vertically in a displacement control mode with $0.05 \mathrm{~mm}$ per step and then the failure process and stress-strain curve of the rock mass before grouting are obtained. Figure 4 shows the failure process of fractured rock under uniaxial 


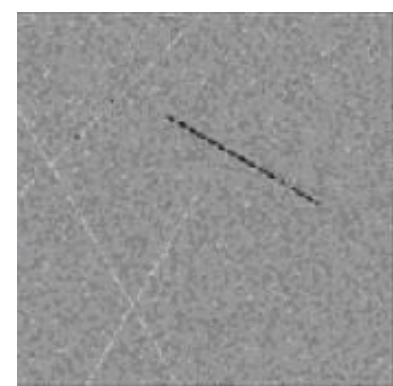

Step 10

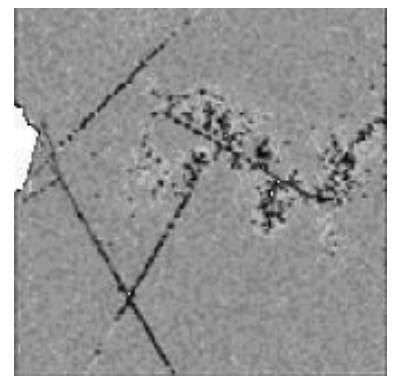

Step 50

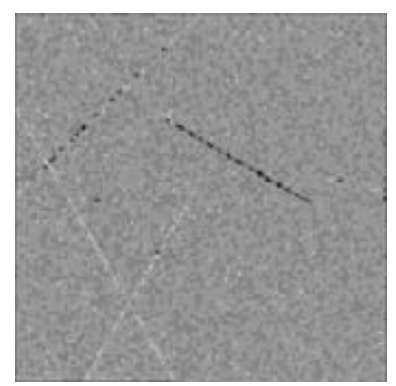

Step 20

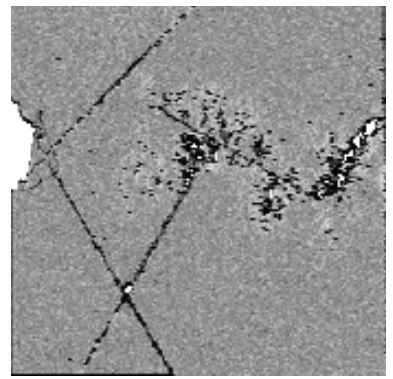

Step 60

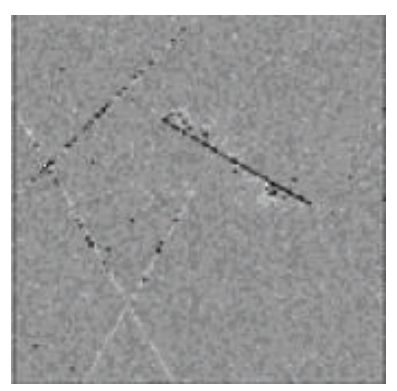

Step 30

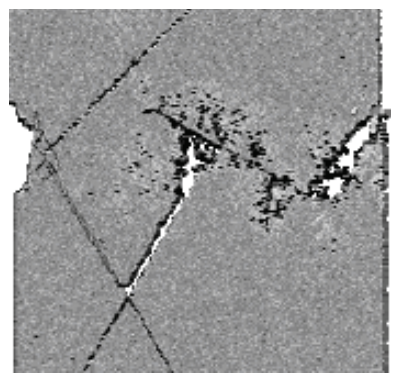

Step 70

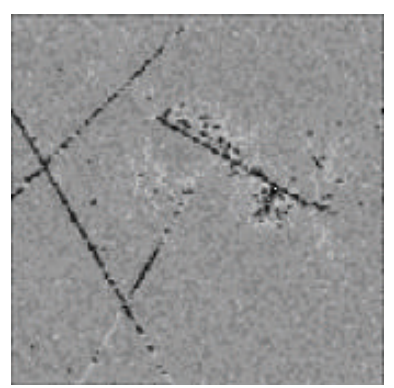

Step 40

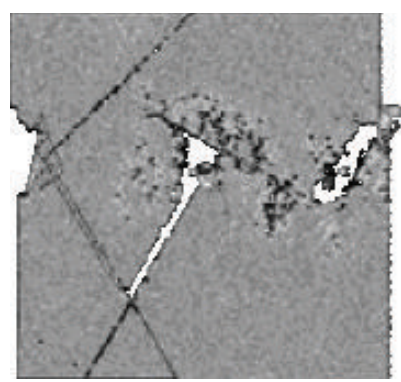

Step 80

FIgURE 4: Failure process of fractured rock under uniaxial compression.

TABLE 1: Mesoproperties for rock mass.

\begin{tabular}{lccc}
\hline Ingredient & $\begin{array}{c}\text { Mean elastic } \\
\text { modulus } \\
(\mathrm{Gpa})\end{array}$ & $\begin{array}{c}\text { Mean } \\
\text { strength } \\
(\mathrm{MPa})\end{array}$ & $\begin{array}{c}\text { Homogeneity } \\
\text { index }\end{array}$ \\
\hline Rock particle & 60 & 400 & 3 \\
Random cracks & 1 & 0.1 & 3 \\
Cement slurry & 20 & 60 & 3 \\
\hline
\end{tabular}

compression, while Figure 5 is the stress-strain curve of the specimen.

It can be seen from the whole failure process that the failure process and failure mode of the specimen are mainly under the control of preexisting cracks C3 and C4. The numerical experiment once again proves that the failure of the rock structure always depends on the inner weak structural planes. The initial elastic modulus of the fractured rock mass is about $45 \mathrm{GPa}$ and the strength is about $55 \mathrm{MPa}$.

The initial cracks are filled with cement slurry after grouting. Figure 6 illustrates the failure process of grouted rock under uniaxial compression and Figure 7 shows the stress-strain curve of the grouted rock mass.

Figure 6 shows that the preexisting cracks are filled with cement slurry after grouting, though the strength and elastic modulus of the cement slurry are much lower than those of rock particles (as shown in Figure 6, the darker the color, the bigger the value). Instead of cement slurry elements, the elements with higher elastic modulus but lower strength fail first. The distributions of strength and elastic modulus are independent, and elements with high elastic modulus may have low strength and vice versa. Therefore, at the initial stage of loading when the stress is low, some elements with

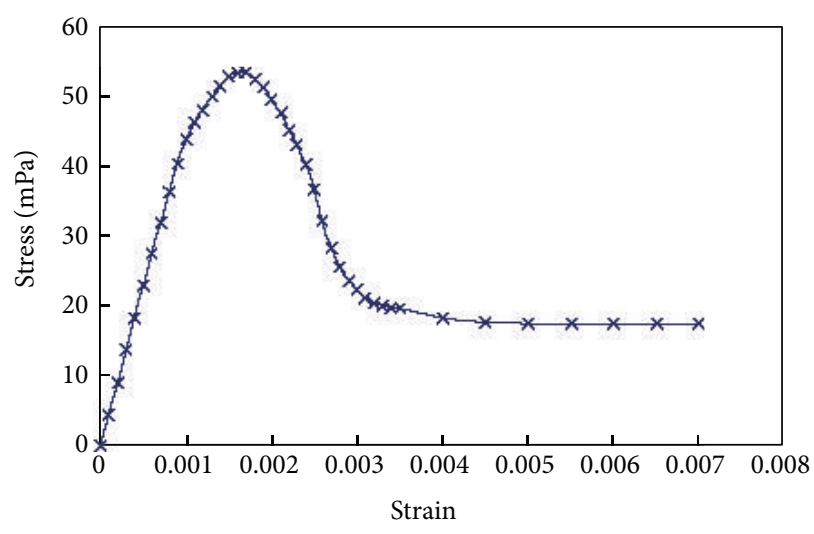

FIGURE 5: Stress-strain curve of the fractured rock.

high elastic modulus and low strength will fracture first. The damaged elements are random in the specimen at the initial stage. With the displacement increase, the random cracks propagate, coalesce, connect, and form a macrodamage belt with big width finally.

Cement slurry fills into the initial cracks of natural fractured rock mass, and weak structure planes which have significant influence on the mechanical characteristics and failure mode of rock mass will no longer exist. The mechanical characteristics of grouted rocks are close to those of integrate rock blocks.

The macroelastic modulus of the grouted rock is about $49.3 \mathrm{GPa}$ and the strength is $122 \mathrm{MPa}$. It is obvious that the elastic modulus is improved by $10 \%$, and at the same time, the strength is improved by $120 \%$. 


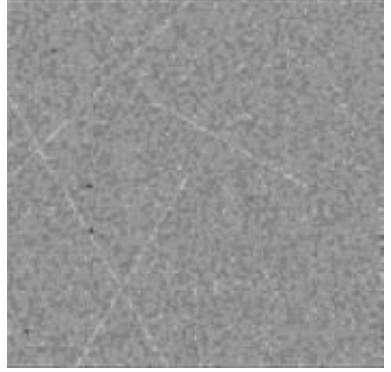

Step 10

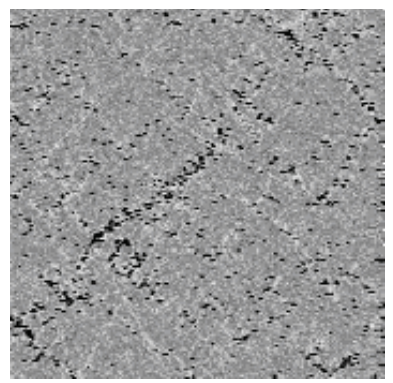

Step 70

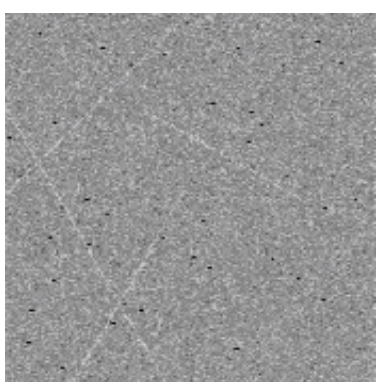

Step 20

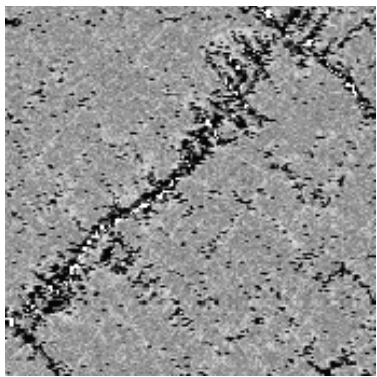

Step 80

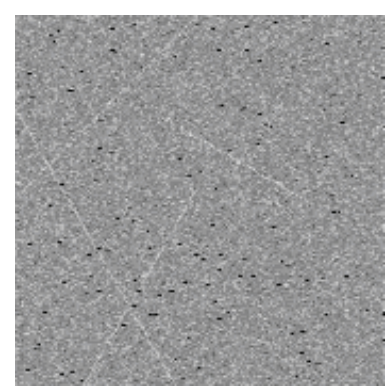

Step 50

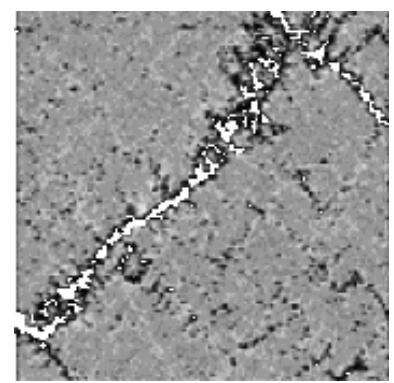

Step 90

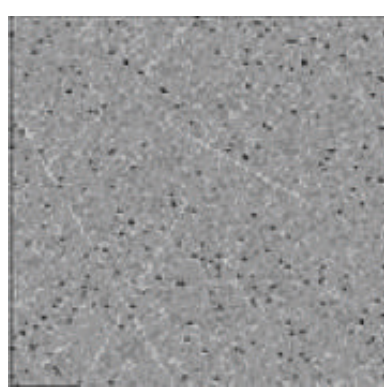

Step 60

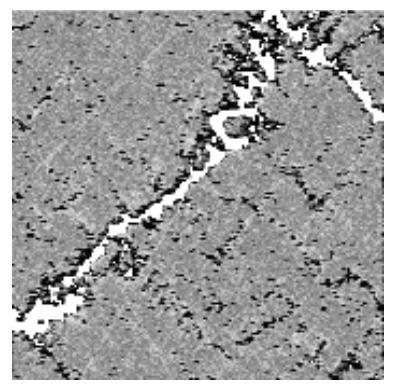

Step 100

FIGURE 6: Failure process of grouted rock under uniaxial compression.

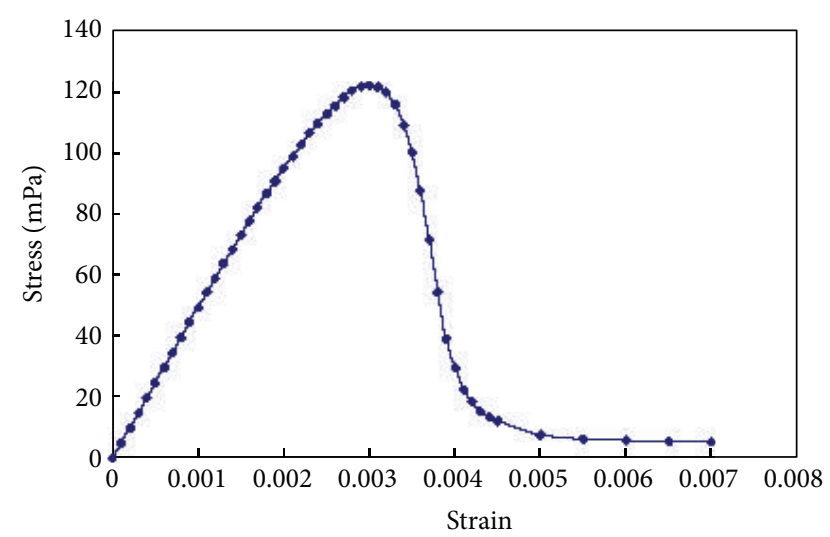

FIGURE 7: Stress-strain curve of grouted rock.

\section{Conclusions}

Mechanical characteristics of engineering rock mass are always under the control of the initial weak structure planes inside; grouting can fill the initial microcracks, enhance integrity of the rock mass, and, thus, change the failure mode and improve the mechanical characteristics of rock mass. In this paper, rock mass is assumed as a composite material consisting of rock particles and random microcracks initially. After grouting, parts or all of the initial microcracks will be filled with cement slurry, and then the grouted rock mass consists of rock particles, grout condensate materials. Based on the theory of mesoscopic damage mechanics, the influence mechanism of the grouting on the mechanical characteristics of rock mass is studied. Of course, the initial distributions of microcracks, grouting effect, and grouting materials have effects on the variation of mechanical characteristics.

Grouting can enhance not only elastic modulus and strength of the rock mass but also the seepage characteristics. This paper only studies the change of the elasticity modulus and strength preliminarily, and the grouting influence on the seepage characteristics needs further research.

\section{Acknowledgment}

This paper is supported by Open Foundation of State Key Laboratory of Hydrology-Water Resources and Hydraulic Engineering (2011491211).

\section{References}

[1] S. Yin and Z. Wen, "Properties and reaction mechanism of dolomite limestone-water glass grout," Chinese Journal of Geotechnical Engineering, vol. 24, no. 1, pp. 76-80, 2002 (Chinese).

[2] J. Ge, "Development and prospect of chemical grouting techniques," Chinese Journal of Rock Mechanics and Engineering, vol. 25, no. 2, pp. 3384-3392, 2006 (Chinese).

[3] D. Tang, "Application of grouting technique to treatment of limestone cave surge," Chinese Journal of Rock Mechanics and Engineering, vol. 25, no. 2, pp. 3583-3586, 2006 (Chinese).

[4] C. Hao, "High pressure grouting technique for fault stabilization treatment at karstic ground," Rock and Soil Mechanics Supplement, vol. 24, pp. 110-112, 2003 (Chinese).

[5] Z. Hao, J. Wang, and X. He, "Computerized simulation of crack grouting in rock mass," Chinese Jounal of Geotechnical Engineering, vol. 21, no. 6, pp. 727-730, 1999 (Chinese). 
[6] M. J. Yang, Y. N. He, and M. X. Chen, "Law of grouting penetrating through fracture network of rock mass," Journal of Hydraulic Engineering, no. 7, pp. 41-46, 2001 (Chinese).

[7] P. Luo, S. He, and Z. Wei, "Present situation of study on grouting theories in rock masses and its prospect," Journal of Shandong Institute of Mining and Technology, vol. 24, no. 1, pp. 47-48, 2005 (Chinese).

[8] P.-P. Luo, Y. Zhu, Y. Zhao, and S. He, "Numerical simulation of grouting in rock mass," Chinese Journal of Geotechnical Engineering, vol. 27, no. 8, pp. 918-921, 2005 (Chinese).

[9] J. Li, J. Xu, Y. Wang, and S. Zou, "Research on crack grouting in concrete dams," Journal of Hydroelectric Engineering, vol. 26, no. 3, pp. 63-68, 2007 (Chinese).

[10] N. Li, P. Zhang, and J. Yan, "Numerical modeling of grouting in geoengineering," Chinese Journal of Rock Mechanics and Engineering, vol. 21, no. 3, pp. 326-330, 2002 (Chinese).

[11] W. Zhu, Q. Zhao, and C. Tang, "Mechanical model and numerical imulation of fracture process of concrete," Advances in Mechanics, vol. 32, no. 4, pp. 579-598, 2002 (Chinese).

[12] J. P. Chen, "3-D net work numerical modeling technique for random discontinuities of rock mass," Chinese Journal of Geotechnical Engineering, vol. 23, no. 4, pp. 397-402, 2001 (Chinese).

[13] B. Hu, S. Wang, S. Liu et al., "Determination and application of jointed rock mass parameters based on fine structure description and numerical experiment," Chinese Journal of Rock Mechanics and Engineering, vol. 26, no. 12, pp. 2458-2465, 2007 (Chinese).

[14] E. Schlangen and J. G. M. van Mier, "Simple lattice model for numerical simulation of fracture of concrete materials and structures," Materials and Structures, vol. 25, no. 9, pp. 534-542, 1992.

[15] S. C. Blair and N. G. W. Cook, "Analysis of compressive fracture in rock using statistical techniques: part 2. Effect of microscale heterogeneity on macroscopic deformation," International Journal of Rock Mechanics and Mining Sciences, vol. 35, no. 7, pp. 849-861, 1999.

[16] C. A. Tang and P. K. Kaiser, "Numerical simulation of cumulative damage and seismic energy release during brittle rock failure-part 1: fundamentals," International Journal of Rock Mechanics and Mining Sciences, vol. 35, no. 2, pp. 113-121, 1998.

[17] Y. Q. Chen, X. P. Zheng, and Z. H. Yao, "Numerical simulation of failure processes in 3-D heterogeneous brittle material," Acta Mechanica Sinica, vol. 34, no. 3, pp. 351-361, 2002 (Chinese).

[18] T. Xu, C. Tang, S. Wang, and Y. Zhang, "Numerical tests on confining pressure effect in rock failure process," Journal of Central South University of Technology, vol. 35, no. 5, pp. 840844, 2004 (Chinese). 


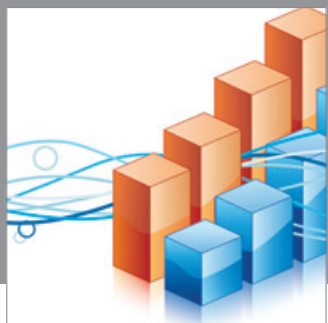

Advances in

Operations Research

mansans

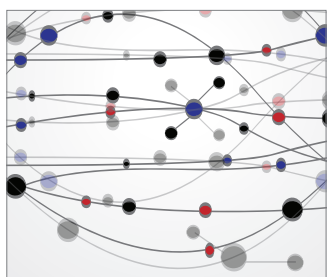

The Scientific World Journal
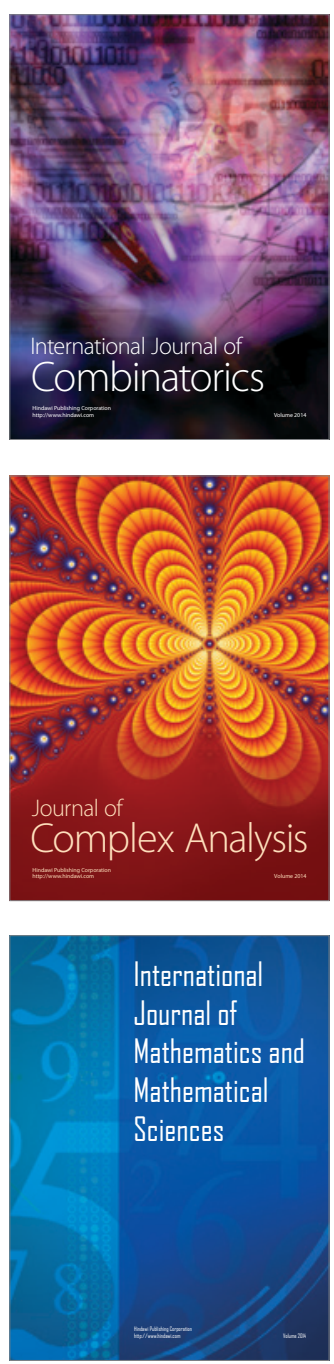
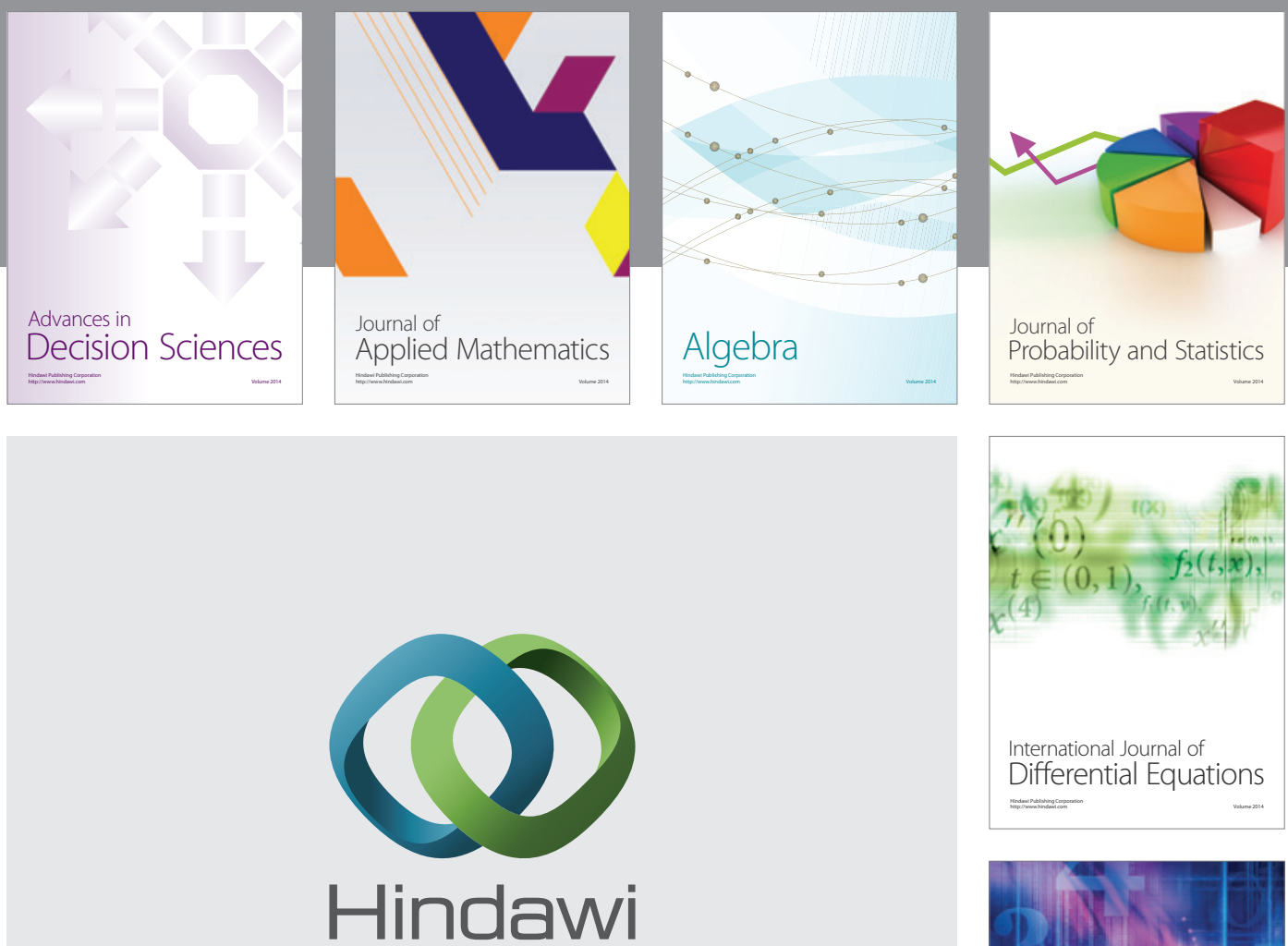

Submit your manuscripts at http://www.hindawi.com
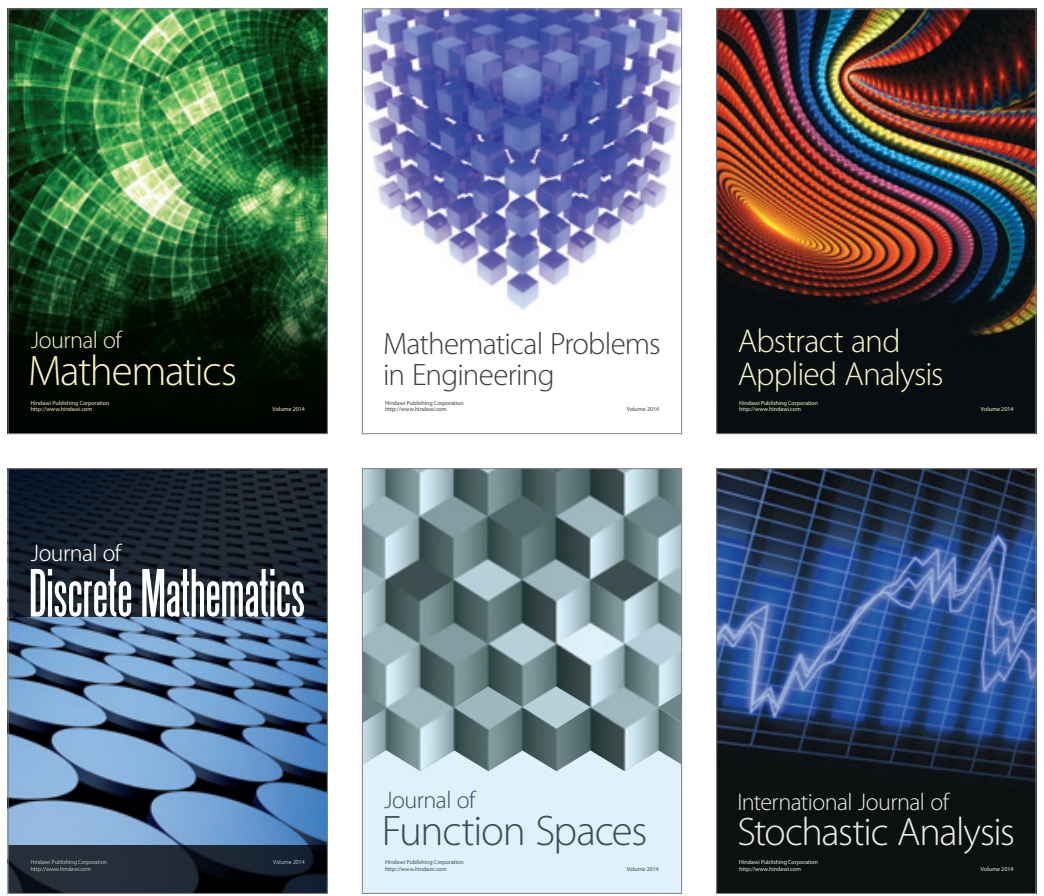

Journal of

Function Spaces

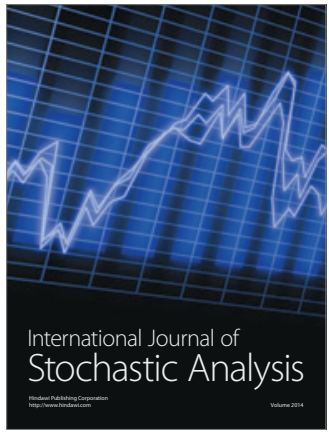

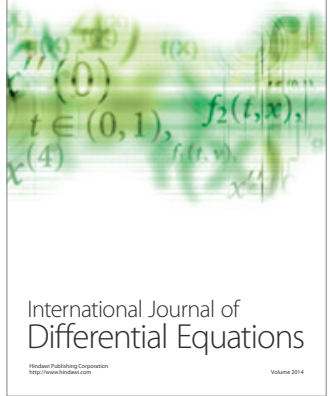
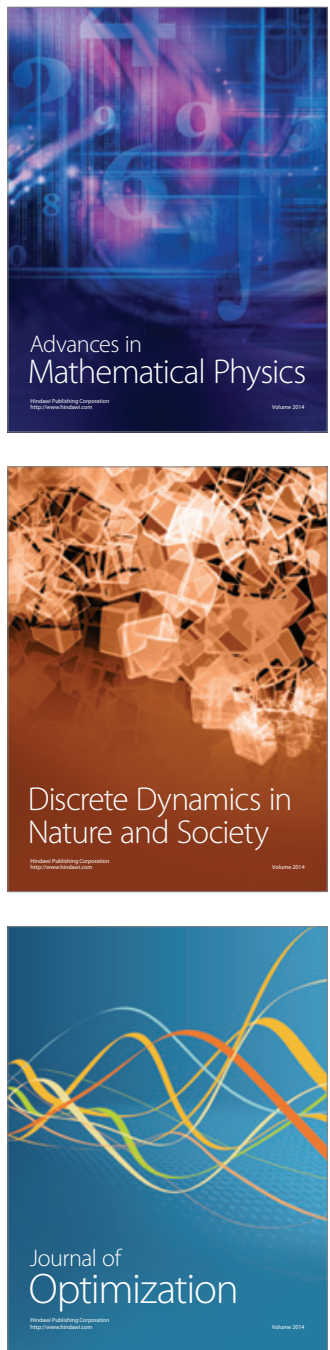